\title{
Full Cell Parameterization of a High-Power Lithium-Ion Battery for a Physico-Chemical Model: Part I. Physical and Electrochemical Parameters
}

\author{
Johannes Schmalstieg, ${ }^{1,2}$ Christiane Rahe, ${ }^{2,3}$ Madeleine Ecker, ${ }^{1,2}$ \\ and Dirk Uwe Sauer ${ }^{1,2,3,4, z}$ \\ ${ }^{I}$ Electrochemical Energy Conversion and Storage Systems Group, Institute for Power Electronics and Electrical Drives \\ (ISEA), RWTH Aachen University, 52066 Aachen, Germany \\ ${ }^{2}$ Jülich Aachen Research Alliance, JARA-Energy, Germany \\ ${ }^{3}$ Helmholtz Institute Münster (HI MS), IEK-12, Forschungszentrum Jülich, 48149 Münster, Germany \\ ${ }^{4}$ Institute for Power Generation and Storage Systems (PGS), E.ON ERC, RWTH Aachen University, Aachen, Germany
}

Physico-chemical models are key for a successful use of lithium-ion batteries, especially under extreme conditions. For correctly simulating of the internal battery states and battery aging a suitable set of material properties is needed. This work presents methods to extract these parameters from commercial cells and demonstrates them analyzing a high-power prismatic cell. In a first step, the electrolyte analysis is described, followed by an examination of the active material. The composition as well as the porous structure are measured using optical emission spectroscopy and Hg-porosimetry. To determine the electrochemical properties of the electrode materials, coin cells with lithium as counter electrode are build. With these test cells, open circuit voltage curves and galvanostatic intermittent titration technique measurements are performed to determine the electrode balancing as well as the diffusion constants of the active material. Electrochemical impedance spectroscopy experiments on the full cell are used to determine the charge transfer. In the second part of this paper, a determination of the thermal parameters as well as a validation for the complete parameterization are described.

(C) The Author(s) 2018. Published by ECS. This is an open access article distributed under the terms of the Creative Commons Attribution 4.0 License (CC BY, http://creativecommons.org/licenses/by/4.0/), which permits unrestricted reuse of the work in any medium, provided the original work is properly cited. [DOI: 10.1149/2.0321816jes]

(cc) BY

Manuscript submitted October 3, 2018; revised manuscript received November 12, 2018. Published December 10, 2018.

Physico-chemical models can depict the behavior of lithium-ion batteries by describing fundamental processes such as lithium diffusion and intercalation. They thus enable the observation of internal states such as local lithium concentrations and potentials, which are hardly measurable in the full cell. Therefore, they are an important tool for understanding cell behavior and use under extreme conditions, such as rapid charging in the context of electromobility. Since the introduction of this model class by Newman and Tiedemann $1975^{1}$ many continuative works have been published. ${ }^{2-10}$

A very important point in the use of physico-chemical models, however, is their parameterization. While the formulation of the model equations can also be dealt with abstractly for all batteries of one type, the parameterization must be carried out individually for each specific cell under consideration. Without an exact knowledge of the individual material parameters, statements about internal states are only possible to a very limited extent. Very little literature ${ }^{11,12}$ has so far dealt with the complete parameterization of specific lithium-ion batteries. In most cases, however, physico-chemical models are used with material parameters that were collected from different sources of literature, guessed or determined by fitting.

Many previous publications studying material parameters only refer to a specific material which is used in a certain type of lithium-ion batteries. In some cases, the intended application for the battery is not taken into account while designing the experiments. However, simulations based on this parameterization approach are questionable since the cell's materials can often not be identified specific enough. For many parameters, e.g. rate of lithium diffusion in graphite, results vary in a wide range. ${ }^{13-17}$ Especially parameters such as the electrode geometry and porosity cannot be measured at all without reference to a specific cell and therefore have to be determined from the battery under consideration.

In contrast to Refs. 11 and 12 where a high-energy pouch cell was analyzed, this work determines parameters of a commercial highpower prismatic cell with $28 \mathrm{Ah}$, which is intended for PHEV usage. After a brief description of the cell opening, the analysis of the electrolyte is presented. Subsequently, the parameters of the electrodes and active materials such as porosity, open circuit voltage (OCV) and

${ }^{\text {z} E-m a i l: ~ b a t t e r i e s @ i s e a . r w t h-a a c h e n . d e ~}$ diffusion rate are determined. Measurements of the full cell are used to determine the exchange current density as well as the balancing of the electrodes. Finally, literature values are used for parameters that could not be determined with the available laboratory equipment.

This work is a translated extract of the German language PhD thesis Ref. 18. This first part of the papers covers the different methods used for examining the single material properties and the results for the specific cell under investigation. In the second part of the paper ${ }^{19}$ the thermal parameters of the cell are analyzed and the validation of the full parameterization is given.

\section{Cell Opening}

Two cells were opened for the parameterization. The first cell was previously discharged to $0 \mathrm{~V}$. On this cell, the geometrical dimensions and weights were determined and an electrolyte sample was taken. The second cell was discharged step by step with decreasing currents to the end of discharge voltage. A remaining voltage of $3.171 \mathrm{~V}$ was measured directly before opening. From this cell, all further samples were taken for later examinations. The openings as well as the further sampling took place in an argon-filled glove box.

\section{Electrolyte Analysis}

The basic problem of electrolyte analysis of commercial lithiumion batteries is the small amount of available electrolyte. The electrolyte is estimated to add $9.9 \%{ }^{20}$ respectively $16 \%^{21}$ to the material costs of a lithium-ion battery. Therefore, like all other materials, it is used as economically as possible. Only a limited quantity is introduced into the cell which is just sufficient for filling the porous structure of electrodes and separator. Free electrolyte for experimenting is found rarely, usually swipe samples from the coil or the housing must suffice. For this work, the solvent components of the electrolyte were determined from a wiping test. Larger quantities were then reproduced to measure the conductivity.

Components.-The sampling took place as early as possible after taking the coil out of the cell housing. It was carried out as a wiping test of wet spots in the housing as well as on the coil. Subsequently, 
Table I. Solvent components (weight-\%) from samples of two cell openings and a commercial electrolyte

\begin{tabular}{cccc} 
& 1st cell & 2nd cell & BASF LP71 \\
\hline DMC & $39.4 \%$ & $35.9 \%$ & $32.8 \%$ \\
EMC & $30.8 \%$ & $30.9 \%$ & $32.1 \%$ \\
DEC & & & $35.1 \%$ \\
EC & $29.8 \%$ & $33.2 \%$ &
\end{tabular}

the wipes were stored in air-tight packaging and later analyzed by gas chromatography (Perkin Elmer Clarus 680 + Clarus 600C).

The gas chromatography was previously calibrated for the four commonly used solvents, dimethyl carbonate (DMC), ethyl methyl carbonate (EMC), diethyl carbonate (DEC), and ethylene carbonate (EC). For comparison, a commercial electrolyte of known composition, LP71 from BASF (EC/DEC/DMC 1:1:122) was also measured. The components DMC, EMC and EC could be detected in the two samples from the investigated cell, the respective percentages are listed in Table I. All three components were present in a similar amount and contributed $30 \%$ to $40 \%$ to the total weight. Assuming a mixing ratio based on integers (see the overview of the available electrolytes from $\mathrm{BASF}^{22}$ ), the mixture analyzed here was interpreted as EC/DMC/EMC 1:1:1.

To determine the conductive salt used in the cell, deposits were washed out from the separator using water and some nitric acid, followed by an inductively coupled plasma optical emission spectroscopy (ICP-OES) elemental analysis. The measurement resulted in a ratio of lithium to phosphor of $95.5 \%$, therefore it is very likely that lithium hexafluorophosphate $\left(\mathrm{LiPF}_{6}\right)$ is the conductive salt.

Conductivity.-For the measurement of the electrolyte conductivity, larger quantities of the electrolyte with different conducting salt concentrations were needed. These could not be extracted from the opened cells, but were mixed according to the components determined in the previous Components section. Electrolyte concentrations from $0.1 \mathrm{~mol} / \mathrm{l}$ to $2 \mathrm{~mol} / \mathrm{l}$ were produced. The components were mixed in glove boxes containing an argon atmosphere.

To determine the conductivity the samples were measured successively in a temperature chamber (BINDER MK 53) using a nitrogen atmosphere. The instrument used was a SevenMulti from Mettler Toledo, which simultaneously recorded conductivity and temperature. For each salt concentration, a temperature ramp of $10^{\circ} \mathrm{C} / \mathrm{h}$ from $5^{\circ} \mathrm{C}$ to $50^{\circ} \mathrm{C}$ was applied to the temperature chamber.

From the recorded temperature-conductivity-curves the conductivity can be extracted as a function of concentration for different temperatures, see Figure 1.

The temperature dependency at $1 \mathrm{~mol} / \mathrm{l}$ is in good agreement with Ref. 23 [p. 83], where a very similar electrolyte (EC/EMC/DMC, 30:35:35 volume-\%, $1 \mathrm{~mol} / \mathrm{L} \mathrm{LiPF}_{6}$ ) was analyzed. Also Valøen et al. ${ }^{24}$ measured similar concentration and temperature dependencies for an electrolyte consisting of propylene carbonate (PC)/EC/DMC (10:27:63 volume-\%) with $\mathrm{LiPF}_{6}$ as conductive salt.

For model implementation and extrapolation to higher conductive salt concentrations, a regression function was chosen based on Ref. 24.

$$
\sqrt{\frac{\sigma_{\mathrm{e}}\left(c_{\mathrm{e}}, T\right)}{c_{\mathrm{e}}}}=a_{1}+a_{2} \cdot T+a_{3} \cdot c_{\mathrm{e}} \cdot T+a_{4} \cdot \exp \left(a_{5} \cdot c_{\mathrm{e}}\right)
$$

Where $\sigma_{\mathrm{e}}$ is the electrolyte conductivity, $c_{\mathrm{e}}$ is the conducting salt concentration and $T$ is the absolute temperature. If the electrolyte conductivity is used in $\mathrm{mS} / \mathrm{cm}$, the conducting salt concentration in $\mathrm{mol} / \mathrm{l}$ and the temperature in $\mathrm{K}$, the following parameters are obtained for the regression function:

$\begin{array}{ccccc}a_{1} & a_{2} & a_{3} & a_{4} & a_{5} \\ -5.384 & 0.03213 & -0.00368 & 1.320 & -2.235\end{array}$

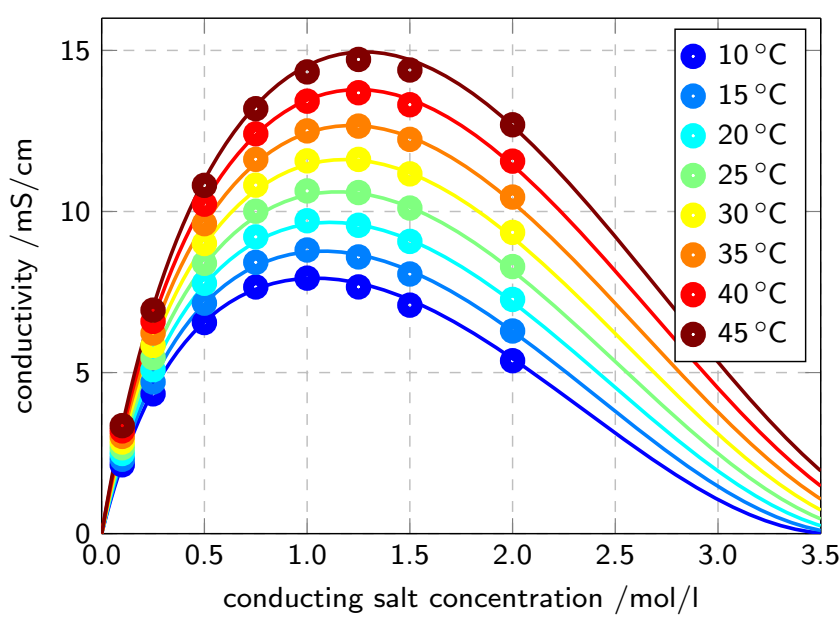

Figure 1. Dependency of the electrolyte conductivity on the conducting salt concentration and temperature. Measured values are shown as points, the lines correspond to the regression function used according to Equation 1.

Diffusion.-Since the electrolyte diffusion coefficient could not be measured directly with the available laboratory equipment, it is derived from the conductivity via the Einstein relationship, ${ }^{25}$ [p. 220 \& p. 212 f.], like in Ref. 11 :

$$
D_{\mathrm{e}}=\frac{\sigma_{\mathrm{e}} \cdot R \cdot T}{F^{2} \cdot z^{2} \cdot c_{\mathrm{e}}}
$$

$D_{\mathrm{e}}$ is the wanted diffusion coefficient, $\sigma_{\mathrm{e}}$ is the measured conductivity, $R$ is the general gas constant, $T$ is the absolute temperature, $F$ is the Faraday constant, $z$ is the charge number and $c_{\mathrm{e}}$ is the lithium concentration in the electrolyte. The Einstein relation is generally only valid for highly dilute solutions, so for the concentrated electrolytes used in lithium-ion batteries it can only be an estimate. The calculated values are for the relevant concentration range around $1 \mathrm{~mol} / \mathrm{l}$ of the same order of magnitude as the measurements of Valøen et al. ${ }^{24}$ which were already mentioned in the previous section. This strengthens the assumption that a good estimation of the diffusion coefficient using the Einstein relationship is possible despite of the high concentrations present.

\section{Active Material Analysis}

Components.-The composition of positive and negative electrode was analyzed by ICP-OES. Five circular specimens of double-coated electrodes were measured, each with a diameter of $2 \mathrm{~cm}$. The samples of the negative electrode were previously washed with DMC. The sample were dissolved in $12 \mathrm{~mL}$ of hot aqua regia, then the samples were diluted to $100 \mathrm{~mL}$ and measured using an ICP-OES (Varian 725-ES).

The soluble components of the electrodes determined this way are listed in Table II. In the anode, the copper current collector was measured, as well as lithium and small amounts of phosphor. The insoluble parts such as carbon, conductive carbon black and binder cannot be measured by this method. In addition to the aluminum current collector, the components of the active material: nickel, cobalt

Table II. Via ICP-OES determined active material compositions from anode (washed) and cathode. The area refers to a single-sided coating, in the case of aluminum and copper to the current collector area.

\begin{tabular}{crrrrrrr} 
& $\mathrm{Al}$ & $\mathrm{Co}$ & $\mathrm{Cu}$ & $\begin{array}{c}\mathrm{Li} \\
\mu \mathrm{mol} / \mathrm{cm}^{2}\end{array}$ & $\mathrm{Mn}$ & $\mathrm{Ni}$ & $\mathrm{P}$ \\
\hline Anode & 0.02 & 0.00 & 70.34 & 5.1 & 0.00 & 0.00 & 0.56 \\
Cathode & 54.69 & 41.94 & 0.03 & 116.6 & 39.30 & 41.24 & 0.15
\end{tabular}




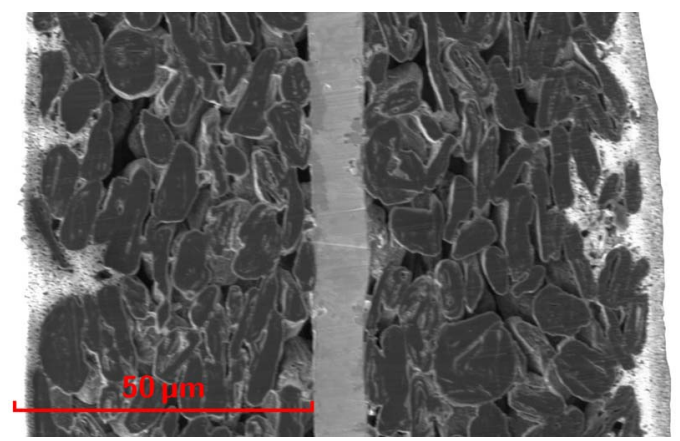

Figure 2. Electron microscopy picture of a cross-section through the anode The fine structure on the surfaces of the electrode is a thin ceramic coating.

and manganese were found in the cathode in a ratio of $1: 1: 1$. This is a classical 111 lithium nickel manganese cobalt oxide (NMC). Assuming a complete lithiation of this material during the assembly process, $95 \%$ of the expected lithium can be found on the cathode and $4.2 \%$ on the anode.

Since in the discharged state all usable lithium is present in the cathode, the lithium found on the anode is probably lithium bound in the solid electrolyte interphase (SEI). As will be seen later, $55 \%$ to $60 \%$ of the lithium present in the cathode is cycled. This results in a formation loss of approximately $7.3 \%$ of the cyclable lithium. In Ref. 12, a lithium loss during the formation of $6.8 \%$ is calculated with a cathode utilization of $74 \%$, resulting in a slightly higher formation loss of $9.2 \%$ of the cyclable lithium.

Assuming that both current collectors consist of a compact foil, the current collector thickness can be calculated to be $10 \mu \mathrm{m}$ for the anode and $11 \mu \mathrm{m}$ for the cathode. These values agree well with electron microscopy pictures of electrode cross-sections (see Fig. 2). Using the ICP-OES data has the advantage to measure an average value over the investigated sample area, while electron microscopy only gives a local thickness.

Porous structure.-The porous structure of electrodes and separator was analyzed by means of mercury porosimetry. The low pressure module Pascal 140 was used in combination with the high pressure module Pascal 440, both from Thermo Fisher Scientific. The evaluation is carried out using the corresponding measuring software SOLID (version 1.3.4). The sample size for the anode and cathode was $42 \mathrm{~mm}$ $\times 90 \mathrm{~mm}$ (double-sided coated) and three samples of this size were used for the measurement of the separator.

The measurements of the electrodes do not only include the porous structure of the coating, but also the solid current collector. For this purpose a correction is made after the measurement, but before the analysis of the data. The weight of the sample $m_{\text {sample }}$ is reduced by the current collector weight $m_{\text {current collector }}$, and the total weight $m_{\text {total }}$ of the dilatometer filled with mercury and sample is increased by the density difference of current collector $\rho_{\text {current collector }}$ and mercury $\rho_{\mathrm{Hg}}$ of the current collector volume $V_{\text {current collector }}$.

$$
\begin{gathered}
m_{\text {sample, cor. }}=m_{\text {sample }}-m_{\text {current collector }} \\
m_{\text {total, cor. }}=m_{\text {total }}+V_{\text {current collector }} \cdot\left(\rho_{\mathrm{Hg}}-\rho_{\text {current collector }}\right)
\end{gathered}
$$

The measurement revealed a significantly intruded volume already at low pressures, these pressures correspond to pores in the order of magnitude of the layer thicknesses and greater. These are interstices between the layers of the sample, since it had to be rolled up in order to fit into the sample holder. Therefore, further analysis was limited to the pressure range of $0.1 \mathrm{MPa}$ to $400 \mathrm{MPa}$, which includes all pores smaller than $15 \mu \mathrm{m}$.

The porosity $\varepsilon$ of the sample is calculated as the ratio between the pore volume $V_{\text {pore }}$ in the selected pressure range and the sample volume $V_{\text {sample }}$, which can also be taken from the mercury porosimetry data.

$$
\varepsilon=\frac{V_{\text {pore }}}{V_{\text {sample }}}
$$

The porosity of the active material layer of the anode was determined from the analysis to $29.2 \%$ and that of the cathode to $20.9 \%$. For the separator a porosity of $39.5 \%$ was calculated. As the sample volume was also determined by the mercury porosimetry and the sample size used was known, the sample thickness could be determined therefrom. The coating thickness of the anode was $46.6 \mu \mathrm{m}$, and that of the cathode $43.0 \mu \mathrm{m}$, each per side. The separator had a thickness of $18.7 \mu \mathrm{m}$. The thickness of the anode and the cathode thus determined is in good agreement with electron microscopy pictures, as it is shown in Figure 2 with an anode cross-section. The porosity of the electrodes is set by the manufacturer via calendering and can vary within a wide range. In Ref. 26, [p. 110 f.], porosities of $18.2 \%$ to $38.4 \%$ are determined by extensive electrode investigations, with a high-power and a high-energy cell being investigated. The comparatively low porosity of the cell measured here corresponds rather to a high-energy design, but with very thin electrodes (see Ref. 26, [p. 143]). The thickness of the separator is below the values given in Ref. 27, [table 1], while the porosity is in good agreement. Also Ref. 28 gives a typical porosity of separators of $40 \%$. Since the cell under investigation is a high-performance cell, the use of a thin separator is very obvious.

In addition to the porosity, the tortuosity is also relevant, which describes the additional influence of the porous structure on effective values for conductivity and diffusion in the electrolyte. The calculation of the tortuosity $\tau$ from the porosimetry data is based on a relation from Carniglia, ${ }^{29}$ which is implemented in the porosimetry evaluation software:

$$
\tau=2.23-1.12 \cdot v_{\text {pores }} \cdot \rho_{\text {sample }}
$$

$v_{\text {pores }}$ is the specific empty volume and $\rho_{\text {sample }}$ is the density of the porous structure. The validity of this relationship is given with:

$$
0.05<v_{\text {pores }} \cdot \rho_{\text {sample }}<0.95
$$

Since both sizes are not directly accessible, a transformation is carried out:

$$
v_{\text {pores }} \cdot \rho_{\text {sample }}=\frac{V_{\text {pores }}}{m_{\text {sample }}} \cdot \frac{m_{\text {sample }}}{V_{\text {sample }}}=\varepsilon
$$

Thus, the calculation of the tortuosity is simplified to a purely linear dependence on the porosity in a range of $5 \%$ to $95 \%$ :

$$
\tau=2.23-1.12 \cdot \varepsilon
$$

Since the calculation of the effective values is implemented in the model using the extended Bruggemann dependency, a corresponding conversion must still be made.

$$
p=1-\log _{\varepsilon}(\tau)
$$

The calculated Bruggemann factor for the anode is 1.52 and 1.44 for the cathode. The separator has a value of 1.62. These values are close to 1.5 , the value expected in the original Bruggemann relationship. For lithium-ion batteries, however, the literature also mentions significantly higher values, e.g. in Ref. 30 in the range of 3 to 4 for different separators. In Ref. 26, tortuosities are given for the electrodes which largely correspond to a Bruggemann factor of approx. 2. By using the relationship from Ref. 29 , porosity and tortuosity are strongly coupled.

The particle radii are calculated using an approach according to Mayer and Stowe. ${ }^{31}$ Assuming spherical particles as well as rectangular openings of the pores, the particle radii $r$ can be calculated by:

$$
r=\frac{\gamma \cdot K_{p}}{p_{\text {cor. }}}
$$

$\gamma$ is the surface tension of the mercury, $p_{\text {cor }}$ is the pressure compensated by the hydrostatic pressure and $K_{p}$ is a compression factor. The 

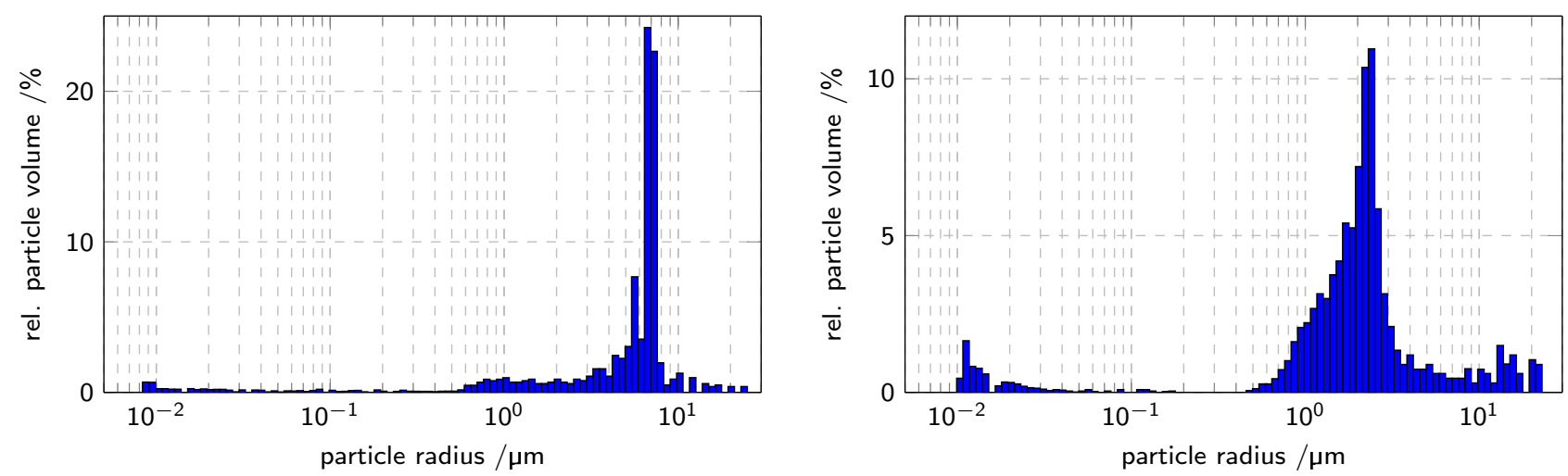

Figure 3. Distribution of the particle radii of the anode (left) and of the cathode (right).

compression factor can be calculated from the contact angle of the mercury (here $140^{\circ}$ ) as well as a compression angle derived from the porosity. An overview of the thus determined distribution of the particle radii of the anode and the cathode is given in Figure 3.

Both electrodes show quite clear maxima in the distribution of the particle radii, being more pronounced for the anode compared to the cathode. For the modeling, the reduction to a particle size per electrode is necessary, therefore the maxima are chosen here. This gives a particle radius of $6.3 \mu \mathrm{m}$ for the anode and $2.13 \mu \mathrm{m}$ for the cathode.

The data of the samples examined in porosimetry as well as the resulting properties of the porous structures are summarized in Table III.

Coin cell assembly. - For the following electrochemical measurements test cells were constructed in the form of coin cells (type CR2025). For this purpose, pieces of anode and cathode were taken from the opened cells under a protective argon atmosphere. The electrodes were de-coated on one side with N-Methyl-2-pyrrolidone (NMP). Samples were then punched with a diameter of $16 \mathrm{~mm}$. Graphite|lithium as well as NMC|lithium coin cells were built from these samples and lithium foil (Rockwood Lithium, thickness 300 $\mu \mathrm{m})$. A $17 \mathrm{~mm}$ diameter Whatman separator (GF/C, $260 \mu \mathrm{m}$ thickness) and $90 \mu 1$ BASF LP71 electrolyte were used.

After the cells were built, an initialization profile took place: Several cycles with $\mathrm{C} / 10$ as well as a pulse test were performed in order to detect defective cells. These were then removed from the test and replaced by reserve cells.

The two types of button cells showed very different reproducibility with regard to the extractable capacity. The graphite|lithium cells had a scattering of $3.9 \mathrm{mAh}$ to $4.25 \mathrm{mAh}$, whereas the NMC|graphite cells were around $3.4 \mathrm{mAh}$.

Open circuit voltage.-Two methods were used to measure the OCV of graphite and NMC. First of all, a slow charge and discharge was carried out, after which a classical OCV measurement of individual state of charge (SOC) took place.

The classical OCV measurement was performed by setting a SOC with a current of $\mathrm{C} / 10$ in steps of $5 \%$. This was followed by a pause of $5 \mathrm{~h}$ for the relaxation, after which the voltage assigned to this SOC

Table III. Sample data (corrected for the current collector) and properties of the porous structure. The thickness refers for the electrodes to the coating on each side.

\begin{tabular}{ccccccc} 
& $\begin{array}{c}\text { Area } \\
\mathrm{mm}^{2}\end{array}$ & $\begin{array}{c}\text { Weight } \\
\mathrm{g}\end{array}$ & $\begin{array}{c}\text { Porosity } \\
\%\end{array}$ & $\begin{array}{c}\text { Thickness } \\
\mu \mathrm{m}\end{array}$ & $\begin{array}{c}\text { Radius } \\
\mu \mathrm{m}\end{array}$ & $p$ \\
\hline Anode & $42 \times 90$ & 0.4868 & 29.2 & 46.6 & 6.30 & 1.52 \\
Cathode & $42 \times 90$ & 1.0071 & 20.9 & 43.0 & 2.13 & 1.44 \\
Separator & $3 \times 42 \times 90$ & 0.1658 & 39.5 & 18.7 & & 1.62
\end{tabular}

was recorded. This measurement was carried out in the charge as well as in the discharging direction.

In addition, a slow-charging and discharging procedure was carried out, in this case with a current of $\mathrm{C} / 100$. This is referred to hereinafter as quasi OCV (qOCV). These measurements cannot provide a real open circuit voltage, since there is always a (albeit very small) current. The deviation, however, should depend on the current and accordingly be very low at small currents.

A comparison of the results of both measurement methods can be seen in Figure 4. The single data points from the OCV and the qOCV measurement are displayed, both for charge and discharge. There is a good agreement between both methods. The advantage of the qOCV is the continuous charging/discharging curve, whereas only single data points are determined by classical OCV measurements.

Another problem going along with the OCV measurement is the behavior at the end of a charge or discharge. The voltages at lithiations of $0 \%$ and $100 \%$ are of interest. However, these cannot be achieved since lithium diffuses from the particle interior to the surface or away from it, and therefore the desired SOCs cannot be measured in a relaxed state. Within a qOCV measurement however, these SOC on the surface of the particles are reached and can therefore be directly recorded, a later relaxation is not relevant here. For this reason, the qOCV measurements are used for the construction of the open circuit voltage curves. qOCV measurements were also used in Ref. 9 as OCV.

Despite the low current during the qOCV measurement, there is a small voltage difference between the charging and discharging curves. In order to generate an open circuit voltage curve from both measurements, these must be combined. In this case, it is assumed that the high voltages (low lithiations) are reproduced best during delithiation (in the charging direction) and the low voltages (high lithiations) are reproduced best during lithiation (in the discharge direction). Therefore the following procedure is used:

- The measured charging and discharging curves are cut in two pieces each. This was done here for graphite as well as for NMC at approximately $60 \%$ lithiation.

- The voltage difference between the charging and discharging direction is determined at this point.

- The range of high voltages of the charging curve as well as the range of low voltages of the discharge curve are each shifted by half the voltage difference so that the two parts are in contact.

- The resulting voltage profile is used as a open circuit voltage curve of the respective material.

The resulting voltage profiles are initially plotted only over the charge throughput between the voltage limits. For the use in the model, however, the OCV curves have to be assigned to the lithiation of the materials. This is no problem for the graphite. Here the voltage limits of $5 \mathrm{mV}$ and $2 \mathrm{~V}$ were related directly to the lithiations $100 \%$ and $0 \%$. However, for NMC only the lower voltage limit of $3 \mathrm{~V}$ could be assigned to a lithiation of $100 \%$. The upper voltage limit was not 

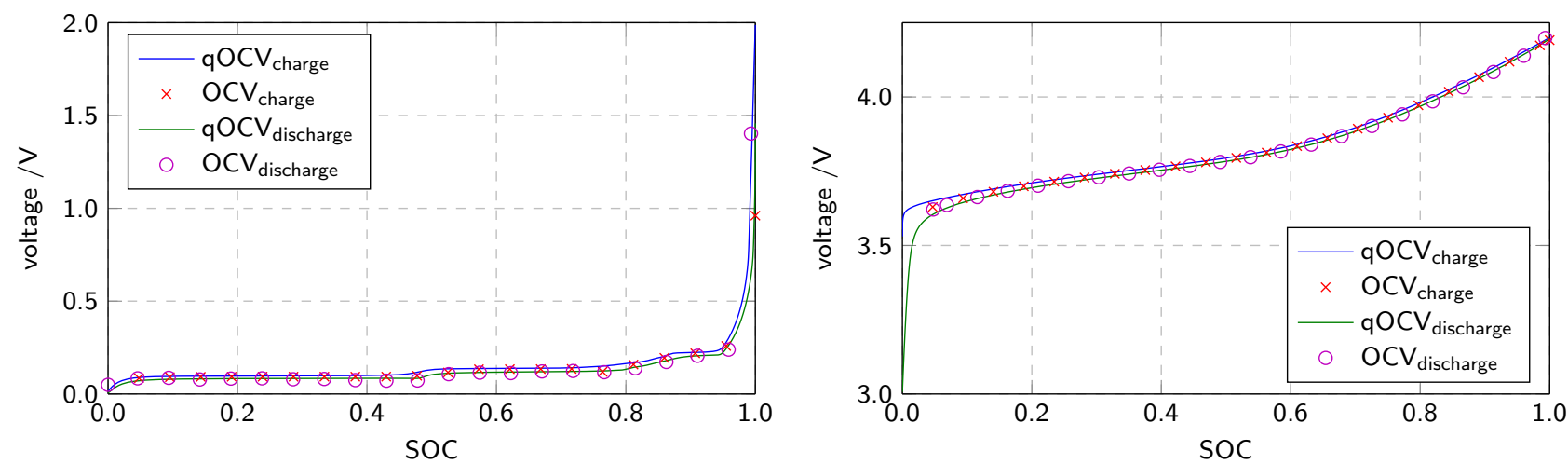

Figure 4. Comparison of the classical OCV and qOCV (C/100) measurement for graphite (left) and NMC (right).

limited by the lithiation of the material, but mainly by the stability of the electrolyte. Therefore, constant voltages of $3.0 \mathrm{~V}$ and $4.2 \mathrm{~V}$ were applied to two NMC|lithium coin cells for several hours. They were then opened and the cathode material was investigated by ICP-OES to determine the ratio between lithium and the NMC components nickel, manganese and cobalt. A ratio of 1:1 (Li:NMC) is found at $3 \mathrm{~V}$ and $0.45: 1$ in the case of $4.2 \mathrm{~V}$. From these two points the lithiation of the NMC corresponding to a certain OCV can be determined. The calculated OCV curves for graphite and NMC are shown in Figure 5.

To implement the OCV into the model, a reduction of the data volume is performed. As mentioned before, the continuous charging/discharging while measuring a qOCV produces a large number of data points, which should be reproduced in the model by a few interpolation points as well as an interpolation between them. The condition for this interpolation is the preservation of the monotony of the curve. In the simplest case, this is possible by a linear interpolation between the reduced data points, but this is only applicable by utilizing many interpolation points. To avoid this, a cubic interpolation is chosen, which can easily reproduce the curve with less support points and is still monotony-sustaining. The method is described in Ref. 32 and is implemented in MATLAB as a function pchip. The interpolation points used as well as the coefficients for the interpolation for the OCV are listed in section S.1 of the supplementary material of Ref. 19.

Diffusion.-The solid-state diffusion coefficient $D$ in the active material is determined by GITT on the graphite|lithium and $\mathrm{NMC} \mid$ lithium coin cells. In a GITT measurement, a short current pulse is given to a cell at rest and the cell voltage is recorded during the current pulse and the subsequent relaxation. The voltage increase during the pulse is divided into an ohmic component $I_{0} R$, which is assumed to be constant, and a part which results from a concentration gradient in the active material. ${ }^{33,34}$

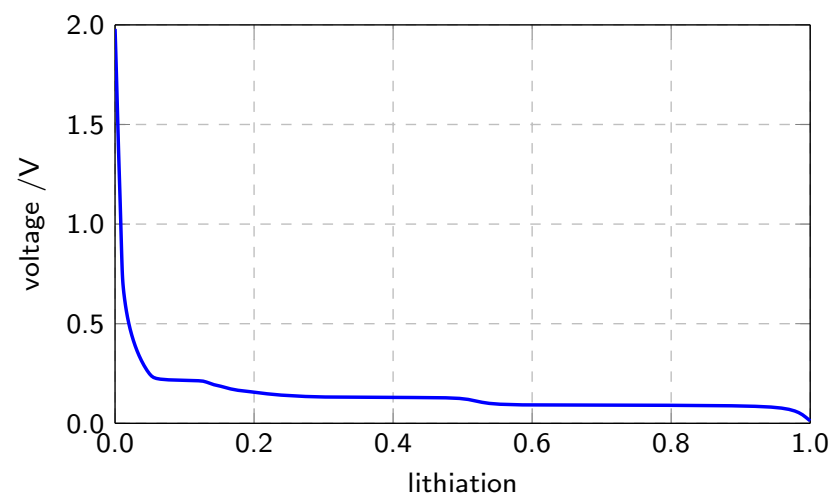

In this work, GITT measurements were performed in increments of $5 \%$ SOC. For this purpose, a four-hour break for relaxation, followed by a C/20 current pulse of $150 \mathrm{~s}$ duration and another relaxation phase of $1 \mathrm{~h}$ is applied to the coins cells. Thereafter, the cells were charged or discharged to the next SOC. These measurements were carried out in the discharge and charge direction.

To calculate the diffusion coefficients $D$ from the GITT measurements, normally

$$
D_{\mathrm{GITT}}=\frac{4 \cdot r^{2}}{\pi \cdot \Delta t} \cdot\left(\frac{\Delta U_{\delta}}{\Delta U_{\Delta t}}\right)^{2} \text { for } \Delta t<<\frac{r^{2}}{D}
$$

is used, ${ }^{11,34}$ where $r$ is the particle radius, $\Delta t$ the pulse length, $\Delta U_{\delta}$ the OCV difference before and after the pulse. $\Delta U_{\Delta t}$ is the voltage increase during the pulse (excluding the ohmic resistance). This equation stems from the assumption of a linear voltage profile over the root of pulse time $\frac{\mathrm{d} U}{\mathrm{~d} \sqrt{t}}=\frac{\Delta U_{\Delta t}}{\sqrt{\Delta t}}$. However, the evaluation shows that this assumption is not valid for all measurements over the whole pulse, as shown, for example, in Figure 6. Assuming the solid-state diffusion as the slower process, a linear regression for $\frac{\mathrm{d} U}{\mathrm{~d} \sqrt{t}}$ in the region $\sqrt{t}$ from 6 $\sqrt{\mathrm{s}}$ to $12.2 \sqrt{\mathrm{s}}$ is done and the evaluation is made with the following modification of Equation 12

$$
D_{\mathrm{GITT}}=\frac{4 \cdot r^{2}}{\pi \cdot \Delta t^{2}} \cdot\left(\frac{\Delta U_{\delta}}{\frac{\mathrm{d} U}{\mathrm{~d} \sqrt{t}}}\right)^{2} \text { for } \Delta t<<\frac{r^{2}}{D}
$$

with $\frac{\mathrm{d} U}{\mathrm{~d} \sqrt{t}}$ being the fitting of the voltage over the square root of time.

The resulting diffusion coefficients for graphite and $\mathrm{NMC}$ at $25^{\circ} \mathrm{C}$ are shown in Figure 7. Both materials show a dependence of the diffusion coefficient $D$ on the lithiation $\delta$.

The diffusion coefficient for NMC shows a linear trend over the lithiation in the semi-logarithmic representation. The values, in particular for high lithiations, are lower in the discharge

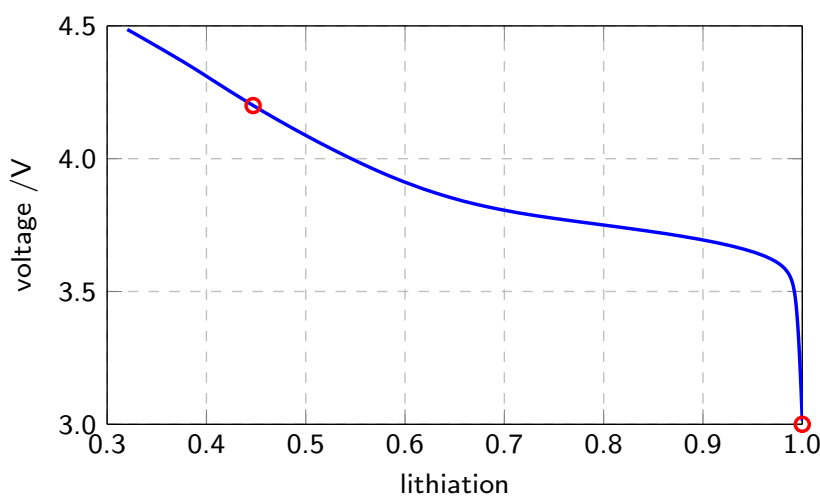

Figure 5. OCV over lithiation for graphite (left) and NMC (right). For the NMC, the two points at which the Li:NMC ratio was determined are also marked. 

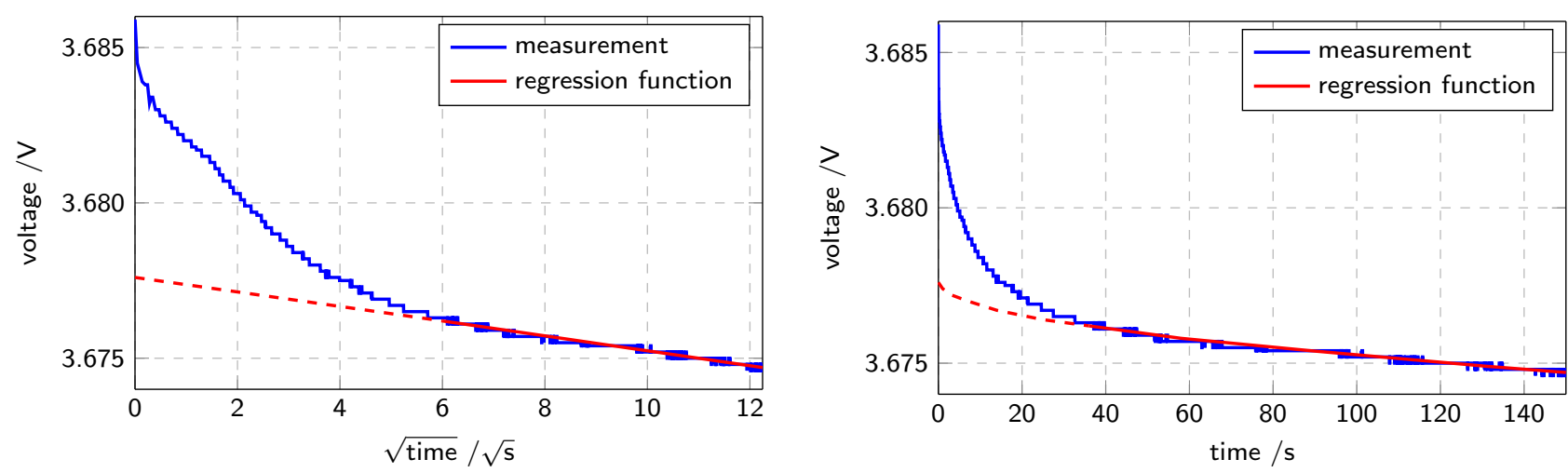

Figure 6. Voltage during a current puls (NMC, 14\% SOC) of the GITT measurement over the square root of time (left) and time (right). In both graphics, the regression function used is also shown.

direction than in the charge direction. For a simple implementation in the model, an exponential (i.e., linear in the semi-logarithmic representation) regression function is selected here. The result of the adjustment is:

$$
\log _{10}\left(D_{\mathrm{NMC}}(\delta) / \mathrm{cm}^{2} / \mathrm{s}\right)=-1.682 \cdot \delta-9.127
$$

The decreasing diffusion coefficients with increasing lithiation are also observed in Ref. 35, with similar values. A slight dependence on lithiation was found by Ref. 36, with a range of $2 \times 10^{9} \mathrm{~cm}^{2} / \mathrm{s}$ to $1 \times 10^{10} \mathrm{~cm}^{2} / \mathrm{s}$ slightly faster than the values observed here. An almost constant diffusion over the lithiation is described in Ref. 37, which is $2 \times 10^{-11} \mathrm{~cm}^{2} / \mathrm{s}$ and slowed down only for full lithiation.

The graphite does not show such a clear trend. As graphite has areas of coexisting phases, were the slope of the OCV is very low, the GITT method is not applicable because of $\frac{\mathrm{d} U}{\mathrm{~d} \delta} \approx 0$. In order to illustrate the areas of coexisting phases, the profile of the OCV, in which the coexisting phases are visible as plateaus, is shown in Figure 7 next to the diffusion coefficient. The corresponding values for the diffusion coefficient in the area of coexisting phases are therefore gray-marked and are not used for model implementation. Since there is no reason why the diffusion in the coexisting phases should be slower than in the adjacent pure phases, the diffusion coefficient of the pure phases is used for this range. The result is a constant diffusion coefficient in the range $1>\delta>0.3$ and an increasing diffusion coefficient for lower lithiation values. This is represented in the model by the following piecewise defined function:

$$
\begin{aligned}
& \log _{10}\left(D_{\text {graphite }}(\delta) / \mathrm{cm}^{2} / \mathrm{s}\right)= \\
& \begin{cases}-3.5 \cdot \delta-8.8 & \delta<0.2 \\
59.375 \cdot \delta^{3}-26.563 \cdot \delta^{2}-8.9125 & 0.2 \leq \delta<0.3 \\
-9.7 & 0.3 \leq \delta\end{cases}
\end{aligned}
$$

The course of the measured values over the lithiation of the graphite shows a good agreement with the GITT measurements from Ref. 13 [p. 93], as well as the publications, Refs. 14 and 15. Probably due to the low resolution, the last two did not detect the acceleration of the diffusion at $55 \%$ and $100 \%$ lithiation. The measurement of Ref. 16 is similar to Ref. 15 but is a factor of three orders of magnitude faster. A range of $10^{-6} \mathrm{~cm}^{2} / \mathrm{s}$ to $10^{-13} \mathrm{~cm}^{2} / \mathrm{s}$ for the diffusion coefficient in graphite is reported in Ref. 17, [p. 206], whereby values around $10^{-8}$ $\mathrm{cm}^{2} / \mathrm{s}$ are described as widely accepted. The large range of reported measurements clearly demonstrates the importance of determining material parameters directly from the cell to be investigated instead of using literature data.

In order to determine the temperature dependence of the diffusion coefficients, further measurements were carried out with identical conditions at $40^{\circ} \mathrm{C}$ and $10^{\circ} \mathrm{C}$. In this temperature range, however, a strong change in the diffusion coefficient could not be observed. In addition, a comparison of the measurements is difficult since the measurements were recorded with some delay and the coin cells showed aging effects. For this reason, a further series of measurements at different temperatures was recorded in which only one SOC was measured.
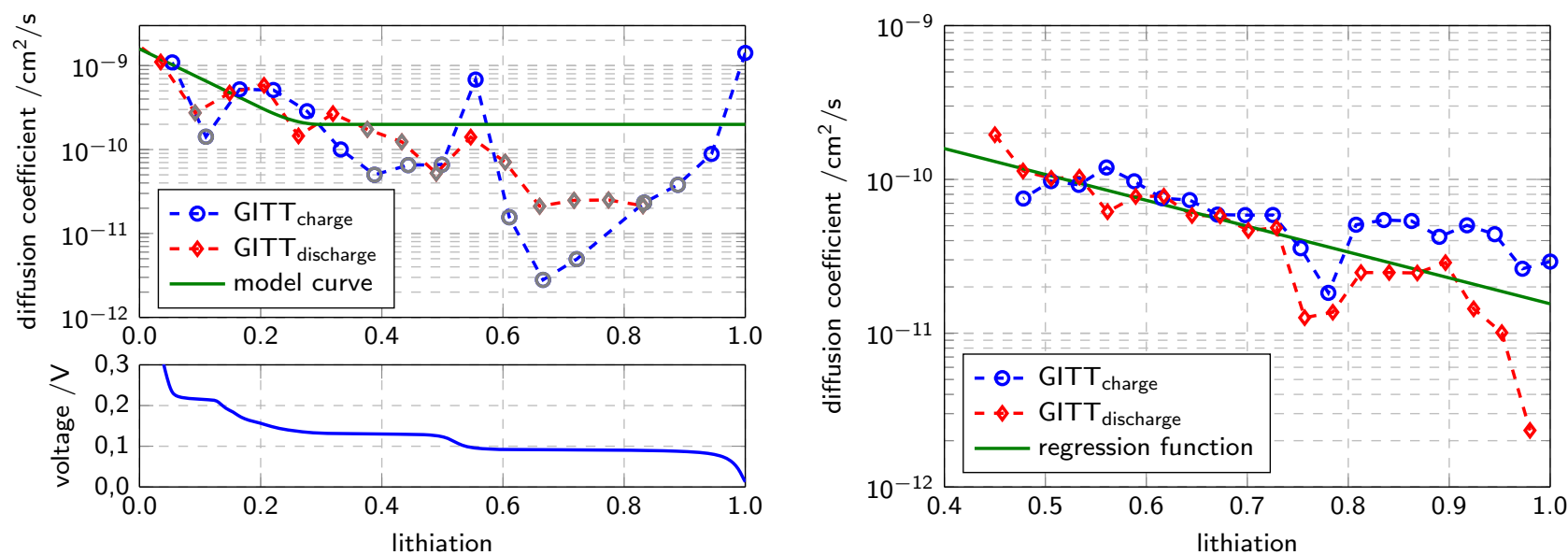

Figure 7. The diffusion coefficient for graphite (left) and NMC (right), determined by GITT, at $25^{\circ} \mathrm{C}$. In addition to the measurements in the charging and discharging direction, the curves derived therefrom for the model implementation are also shown. For the graphite, a section of the OCV is shown to illustrate the areas of coexisting phases. Non-considered data points in the range of coexisting phases are shown in gray. 

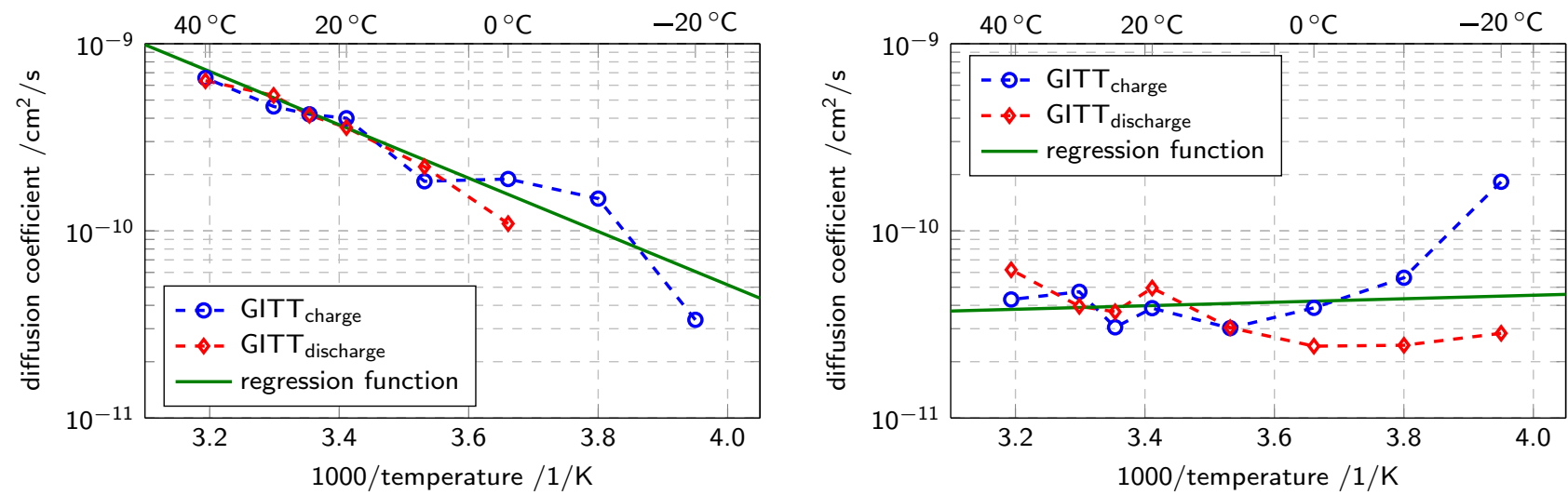

Figure 8. Temperature dependence of lithium diffusion in graphite (left) and NMC (right). Also shown is the resulting regression line for determining the activation energy.

A voltage of $180 \mathrm{mV}$ was chosen for the graphite|lithium coin cells, whereas the $\mathrm{NMC}$ |lithium cells were tested at $3.8 \mathrm{~V}$. This is equivalent to a lithiation of approximately $15 \%$ (graphite) and $70 \%$ (NMC). The measurements were performed in a temperature range of $-20^{\circ} \mathrm{C}$ to $40^{\circ} \mathrm{C}$. The results are shown in Figure 8. A linear regression of the measured values in Arrhenius representation yields activation energies of $28.8 \mathrm{~kJ} / \mathrm{mol}$ for graphite and $-1.89 \mathrm{~kJ} / \mathrm{mol}$ for NMC. In the literature, two sources could be found for the temperature dependence of lithium diffusion in graphite: In Ref. 38 measurements similar to GITT result in $35 \mathrm{~kJ} / \mathrm{mol}$, while in Ref. 39 theoretical calculations give $0.51 \mathrm{eV}$ and $0.49 \mathrm{eV}$ respectively (corresponding to $49.2 \mathrm{~kJ} / \mathrm{mol}$ and $47.3 \mathrm{~kJ} / \mathrm{mol}$ ). Both values are higher than the temperature dependence found here, but this deviation is not particularly high with respect to the differences between the two literature sources and the generally varying values for diffusion coefficients. The activation energy for NMC determined in this work is negative, which corresponds to an acceleration of the diffusion at lower temperatures and thus contradicts all expectations. For NMC only Ref. 40 gives an activation energy for the diffusion process. Ab initio calculations gave an activation energy of $514 \mathrm{meV}$ for $111 \mathrm{NMC}$ at $67 \%$ lithiation. This is equivalent to $49.6 \mathrm{~kJ} / \mathrm{mol}$, which seems to be much more realistic. Therefore, the measured activation energy is replaced by this literature value.

Exchange current density.-The exchange current density is determined by means of electrochemical impedance spectroscopy (EIS) measurements, which were done on the full cells. The spectra of some EIS measurements on full cells at different states of charge and $25^{\circ} \mathrm{C}$ are shown in Figure 9.

In order to determine the charge transfer resistances of both electrodes, the equivalent circuit diagram depicted in Figure 10 was used. The electrodes are represented by the two randles-circuits in the center. There are many free parameters for the adjustment of the equivalent circuit to the measured values. For meaningful starting values the method of distribution of relaxation times (DRT) was therefore used, which allows a finer separation of individual processes. A comprehensive description of the parameter extraction from impedance spectra can be found in Ref. 41.

To assign the charge transfer processes found in the full cell to the two electrodes, measurements of graphite|lithium and NMC|lithium coin cells were used. In the coin cells two processes could be found via DRT, namely the active material and the lithium metal. By comparing the time constants between the coin cells and the full cell, anode and cathode processes could be separated and thus be linked to the full cell.

The Butler-Volmer equation is used to calculate the exchange current density $i_{0}$ from the determined charge transfer resistance $R_{\mathrm{ct}}$ of the full cell:

$$
I_{\mathrm{ct}}=i_{0} \cdot A \cdot\left[\exp \left(\frac{\alpha \cdot z \cdot F}{R \cdot T} \cdot \Delta U\right)-\exp \left(-\frac{(1-\alpha) \cdot z \cdot F}{R \cdot T} \cdot \Delta U\right)\right]
$$

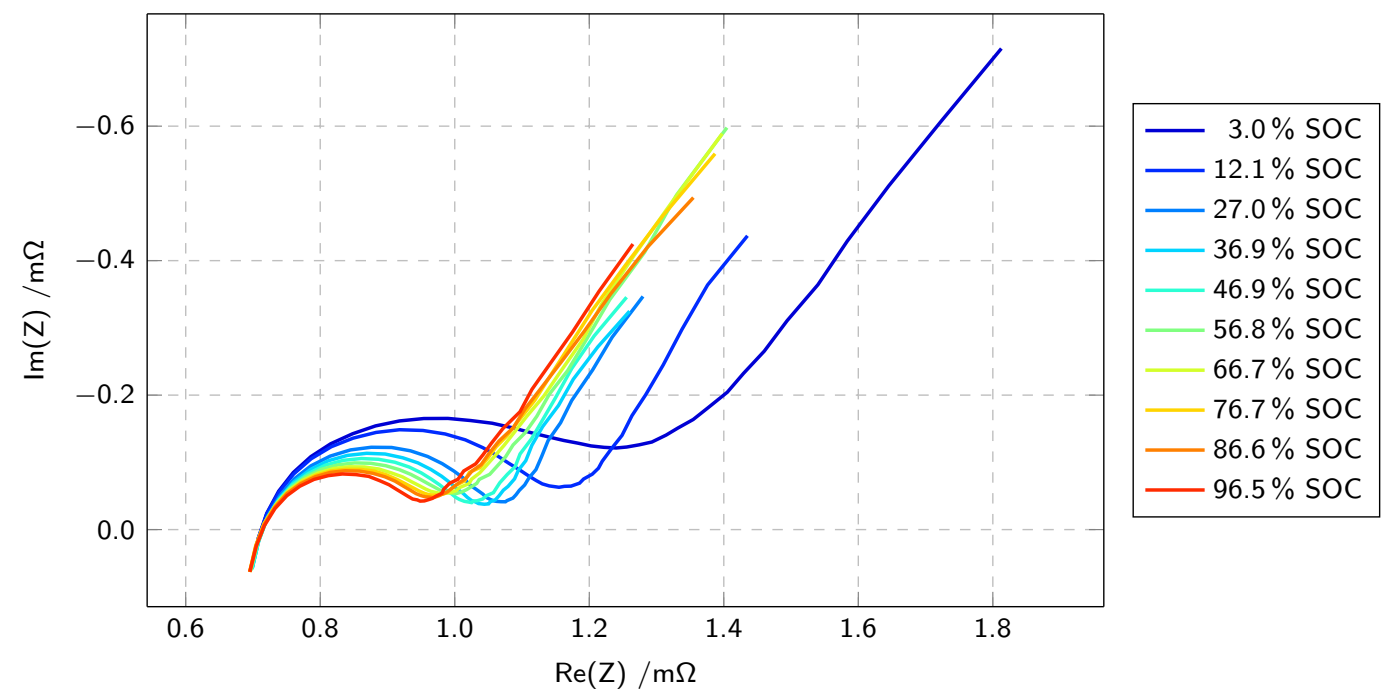

Figure 9. Nyquist-plot of some EIS measurements of a full cell at $25^{\circ} \mathrm{C}$ and excitation frequencies between $800 \mathrm{~Hz}$ and $19 \mathrm{mHz}$. 


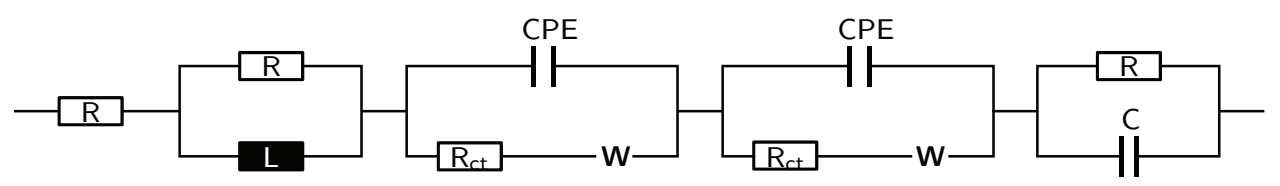

Figure 10. Equivalent circuit diagram for the representation of full cell EIS measurements.

Where $A$ is the contact area between electrode and electrolyte, $z$ is the charge number of the reaction, $F$ respectively $R$ are the Faradayrespectively universal gas constant and $T$ is the absolute temperature. $\alpha$ is the charge transfer coefficient, which is set to 0.5 in the following calculations. For small overvoltages $\Delta U$, which can generally be assumed for EIS measurements, the equation can be approximated to:

$$
I_{\mathrm{ct}}=i_{0} \cdot A \cdot \frac{z \cdot F}{R \cdot T} \cdot \Delta U
$$

By using $R_{\mathrm{ct}}=\frac{\Delta U}{I_{\mathrm{ct}}}$ the relationship between the exchange current density and the charge transfer resistance $R_{\mathrm{ct}}$ can be established:

$$
i_{0}=\frac{R \cdot T}{z \cdot F \cdot A \cdot R_{\mathrm{ct}}}
$$

However, in addition to the charge transfer resistance, the active surface, this means the contact area between the active material and the electrolyte, must also be known for the application of Equation 18. The determination of the active surface is described in a later Active material share section, here only the results (anode $19.43 \mathrm{~m}^{2}$, cathode $61.61 \mathrm{~m}^{2}$ ) are used. The resulting exchange current densities for graphite and $\mathrm{NMC}$ at $25^{\circ} \mathrm{C}$ are shown in Figure 11.

For SOC dependency of the exchange current density, theoretical derivations, ${ }^{42}[$ [p. 354$]$ are used. This publication describes the exchange current density $i_{0}$ dependence from the lithium concentration in the electrolyte $c_{\mathrm{e}}$ as well as in the active material $c_{\mathrm{s}}$, with $k$ being a reaction constant:

$$
i_{0}=F \cdot k \cdot \sqrt{c_{\mathrm{e}} \cdot c_{\mathrm{s}} \cdot\left(c_{\mathrm{s}, \max }-c_{\mathrm{s}}\right)}
$$

A regression curve has been fitted to the calculated values according to Equation 19, which is also shown in the figure. Only a partial correspondence of the measurement points with the compensation curve can be seen. The full data set of the exchange current densities can be found for own fittings in section S.2 of the supplementary material of Ref. 19. The regression curves gives a exchange current density of $7.43 \times 10^{4} \mathrm{~A} / \mathrm{cm}^{2}$ for graphite and of $5.03 \times 10^{-4} \mathrm{~A} / \mathrm{cm}^{2}$ for NMC, both at $50 \%$ lithiation and for the reference electrolyte concentration of $1 \mathrm{~mol} / \mathrm{l}$. For the exchange current density of graphite, Ref. 13 has pointed out the necessity of parameterizing existing materials instead of using literature data, since Ref. 43 could show a strong dependency of the exchange current density on the electrolyte composition. For the simulation of the full cell, an exchange current density for graphite of $5.39 \times 10^{-4} \mathrm{~A} / \mathrm{cm}^{2}$ was chosen in Ref. 13. Ref. 26 found for two graphites $2.76 \times 10^{-4} \mathrm{~A} / \mathrm{cm}^{2}$ and $5.19 \times 10^{-4} \mathrm{~A} / \mathrm{cm}^{2}$ while Ref. 44 used a much lower value of $6.25 \times 10^{-5} \mathrm{~A} / \mathrm{cm}^{2}$. For NMC Ref. 44 gives a exchange current density of $8.19 \times 10^{-5} \mathrm{~A} / \mathrm{cm}^{2}$.

To determine the temperature dependency of the exchange current density, measurements at $5^{\circ} \mathrm{C}, 15^{\circ} \mathrm{C}$ and $25^{\circ} \mathrm{C}$ are analyzed and the values at $50 \%$ lithiation are determined using regression functions. An Arrhenius plot of these data is shown in Figure 12. The regression results in activation energies of $48.9 \mathrm{~kJ} / \mathrm{mol}$ for graphite and 78.1 $\mathrm{kJ} / \mathrm{mol}$ for NMC. There is a wide range of literature values for these activation energies. For graphite Ref. 43 reports values of $45 \mathrm{~kJ} / \mathrm{mol}$ to $60 \mathrm{~kJ} / \mathrm{mol}$, depending on the electrolyte. However, Ref. 44 used $76.8 \mathrm{~kJ} / \mathrm{mol}$. Similar for NMC, where Ref. 45 measured values from $27.4 \mathrm{~kJ} / \mathrm{mol}$ to $36.0 \mathrm{~kJ} / \mathrm{mol}$, depending on the binder used, while Ref. 44 found $57.5 \mathrm{~kJ} / \mathrm{mol}$.

In addition to the exchange current density, the double layer capacitance $C_{\mathrm{dl}}$ can also be determined from the equivalent circuit diagram fitted to the EIS measurement. For this, the charge transfer resistance $R_{\mathrm{ct}}$ and the time constant $\tau_{\mathrm{ct}}$ of this reaction, which was obtained from the DRT analysis, are used again:

$$
C_{\mathrm{dl}}=\frac{\tau_{\mathrm{ct}}}{R_{\mathrm{ct}}}
$$

For the measurements at $25^{\circ} \mathrm{C}$ a capacitance density of $1.47 \mathrm{~F} / \mathrm{m}^{2}$ is found for the negative electrode and of $0.198 \mathrm{~F} / \mathrm{m}^{2}$ for the positive electrode. In Ref. 44 a capacitance density of $0.56 \mathrm{~F} / \mathrm{m}^{2}$ is given for graphite and $41.82 \mathrm{~F} / \mathrm{m}^{2}$ for NMC. Since the calculation is based on the charge transfer resistance and this already clearly differed in Ref. 44, these deviations are not surprising.

As with all surface-related variables, it is important to consider that the real contact area between the active material and the electrolyte can hardly be determined. Instead, assumptions are made, both in the model as well as in the parameterization, such as, e.g. smooth, spherical particles. It is particularly important that identical assumptions are made for the model and parameterization so that the area-related variables in the simulation are recalculated accordingly. This can be seen in the following thought experiment: If instead of smooth surfaces, only surfaces of high roughness and thus a much larger contact area would be found, the area related values for $R_{\mathrm{ct}}$ and $C_{\mathrm{dl}}$ would change.
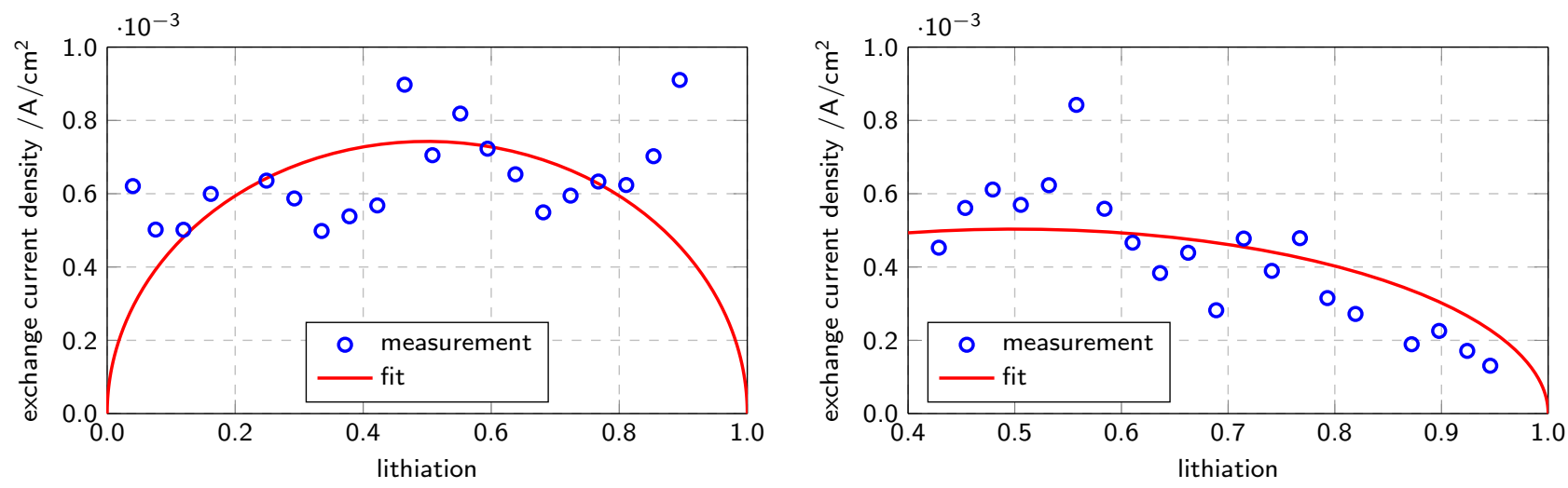

Figure 11. The dependency of the exchange current density at $25^{\circ} \mathrm{C}$ on lithiation for graphite (left) and NMC (right). A regression function of the shape $i_{0} \propto \sqrt{\delta \cdot\left(\delta_{\max }-\delta\right)}$ is also shown. 


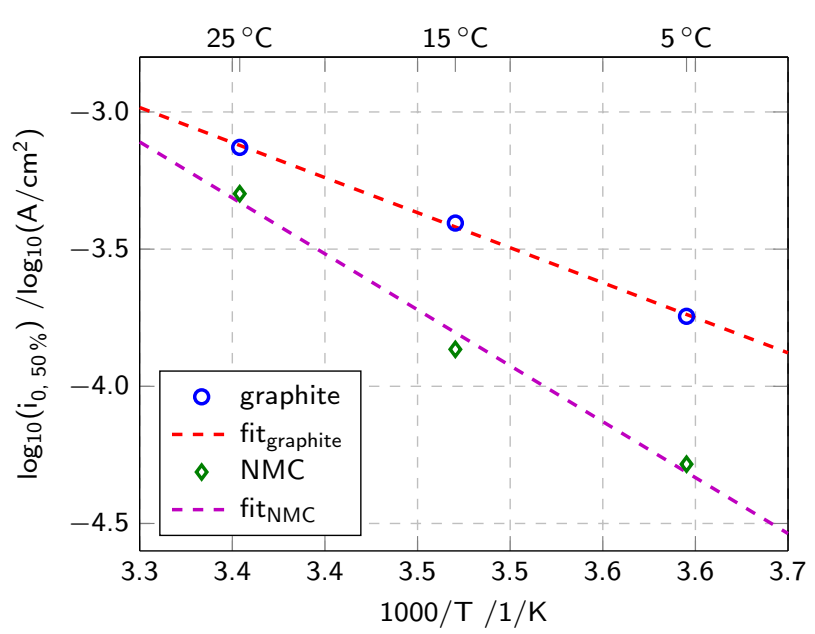

Figure 12. Arrhenius representation of the temperature dependency of the exchange current density for graphite (left) and NMC (right) including a regression function.

But with the corresponding implementation in the model, exactly the same absolute values would be obtained.

\section{Full Cell Analysis}

After investigating the individual materials of the cell, the properties of the full cell are now considered.

Dimensions and weights.-The total weight of the cell before opening was $758.4 \mathrm{~g}$. After the opening of the cell, two parallel coils were found, which were almost equally heavy with weights of $298.7 \mathrm{~g}$ and $298.8 \mathrm{~g}$. After one coil was unwound, a weight of $136.0 \mathrm{~g}$ was measured for the cathode. The anode had a weight of $115.0 \mathrm{~g}$ and the separator of $25.7 \mathrm{~g}$. As a large part of the electrolyte evaporated during the unwinding process, the amount of electrolyte could be estimated to be at least $22.0 \mathrm{~g}$ per coil.

The coated surface was on the anode $391.5 \mathrm{~cm} \times 12.4 \mathrm{~cm}$ and on the cathode $375.0 \mathrm{~m} \times 11.85 \mathrm{~m}$. These data refer to one coil and one side of the double-sided coating.

Balancing.-The balancing of the full cell, this means the capacity of the anode and the cathode as well as their ratio, is determined by an adaptation of the single material OCV to a full-cell qOCV. For the full cell a charge and discharge was performed as qOCV with $\mathrm{C} / 50$. The
OCV of the materials is already known from the previous analysis (see Open circuit voltage section).

Since no reference electrode was present in the full cell, only the total voltage of the cell could be measured, but not the single voltages of positive and negative electrode. The adjustment must therefore be made in such a way that the difference between the two OCV curves of the single electrodes gives exactly the measured fullcell voltage. Modifiable parameters are the capacity of the individual electrodes as well as the shift between the two electrodes caused by irreversible lithium loss. The adjustment is done in a two step process.

In the first step, the negative electrode is adapted, since the voltage curve of the graphite has characteristic points. For this, let us refer again to the OCV curve in Figure 5 (left), where the plateaus of the coexisting phases as well as the transitions in the pure phase are clearly visible. These transitions can be seen more clearly in the voltage change, the derivative $\frac{\mathrm{d} U}{\mathrm{~d} O}$ of the voltage $U$ after the charge throughput $Q$. This is shown in Figure 13 (left), along with the derivatives of the qOCV measurements on the full cell. By means of stretching and shifting the graphite OCV, an adaptation of the negative electrode can be achieved quickly in this representation (the graph shows already the adapted state).

In the second step, the positive electrode is then adjusted. For this purpose the qOCV measurement of the full cell as well as the just determined potential of the negative electrode are used. The addition of these two must correspond to the NMC OCV. Here adaptation takes place via stretching and shifting as well. The result of this adjustment is shown in the Figure 13 (right), where the NMC OCV is shown between the two qOCV measurements of the full cell.

The final result of the adjustment is shown in Figure 14. In addition to the qOCV measurements on the full cell, the calculated full cell OCV as well as the graphite and NMC OCV are shown, each with an own lithiation scale. The graphite is used in a range of $1.4 \%$ to $88.4 \%$ and the NMC from $96.15 \%$ to $43.52 \%$. The difference to the complete lithiation of the NMC is the lithium irreversibly bound to the negative anode in the SEI during formation. The value of approx $4 \%$ is in good agreement with the measurement results of the ICP-OES (see Components section).

In addition to the utilization of positive and negative electrode, also their absolute capacities can be calculated from the determination of the balancing. The capacity determined during the qOCV discharge is $29.86 \mathrm{Ah}$. If the graphite on the negative electrode has a usage of $87 \%$, this results in an electrode capacity of $34.32 \mathrm{Ah}$. Correspondingly, for the NMC of the positive electrode, a capacity of $56.74 \mathrm{Ah}$ is obtained for complete delithiation.

Active material share.-The active material share of the electrode structure is calculated by comparing the measured and the theoretical
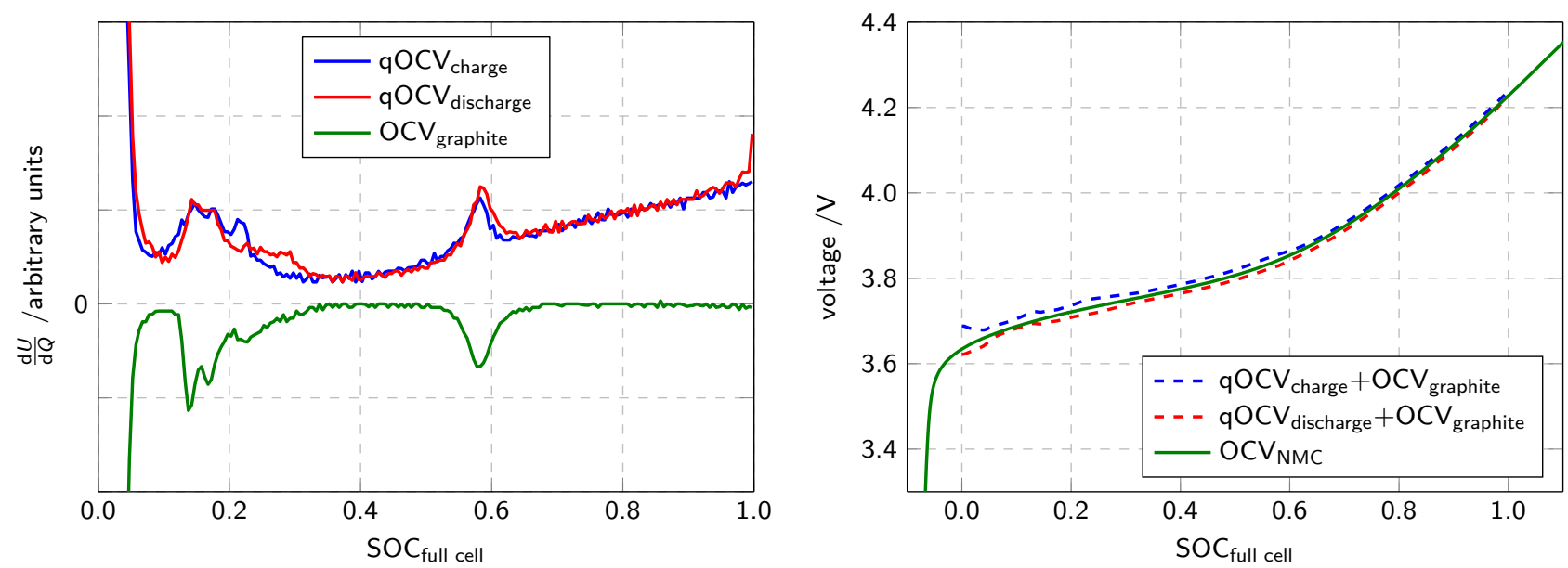

Figure 13. Determination of full cell balancing by fitting the graphite OCV (left) and the NMC OCV (right) to a full cell qOCV. 


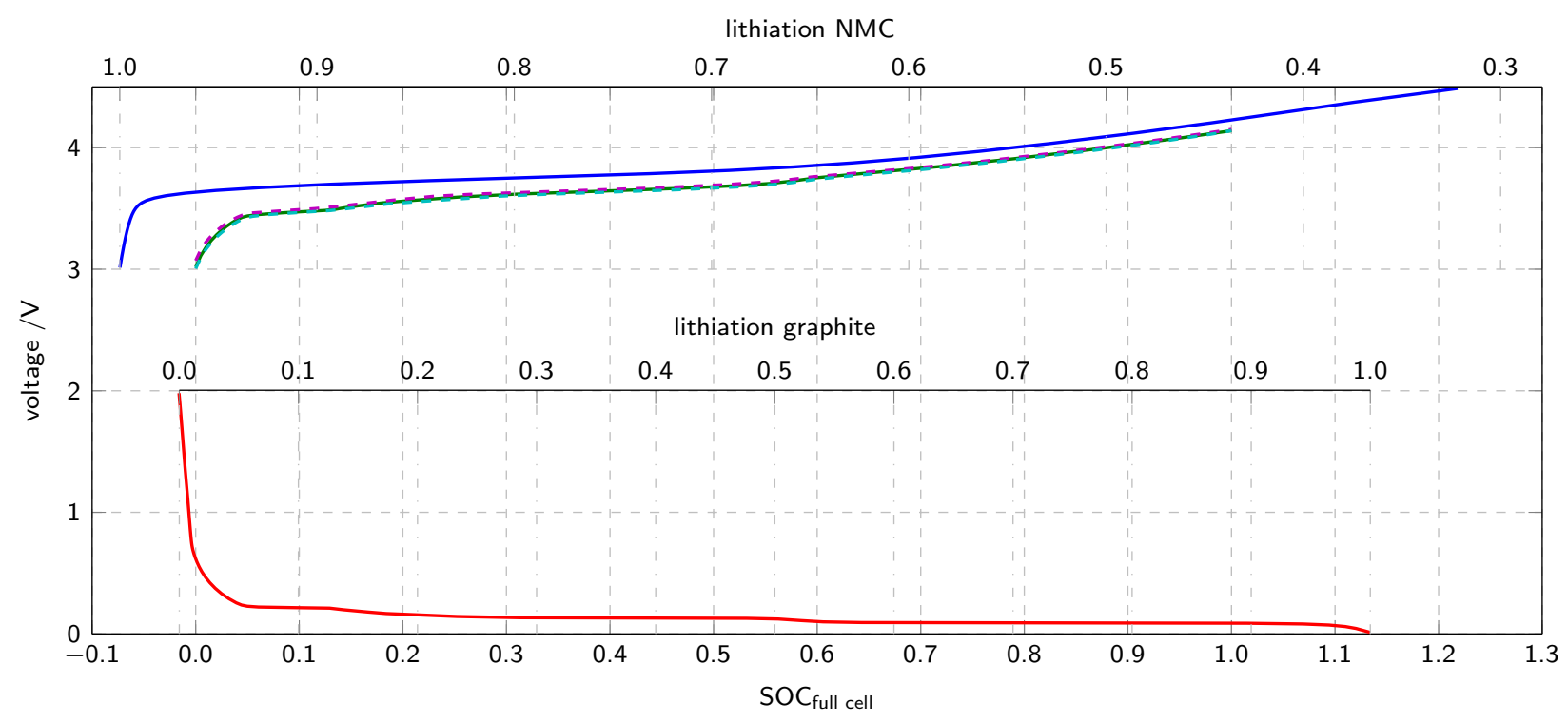

$-\mathrm{OCV}_{\mathrm{NMC}}-\mathrm{OCV}_{\text {graphite }}-\mathrm{OCV}_{\text {calculated }}$ - - - $\mathrm{qOCV}_{\text {charge }}$ - - - qOCV $\mathrm{q}_{\text {discharge }}$

Figure 14. Graphite and NMC OCV over the state of charge of the full cell, together with own lithiation scales. Additionally shown are the resulting OCV of the full cell and the qOCV measurements in charge and discharge direction.

capacity. The theoretical capacity $C_{\text {theo }}$ is determined by:

$$
C_{\text {theo }}=\frac{\rho \cdot V \cdot F}{M}
$$

$\rho$ is the material density of the graphite and NMC, $V$ is the volume of the electrode, $F$ is the Faraday constant and $M$ is the molar mass of the active material. The division $\rho / M$ results in the maximum lithium concentration $c_{\mathrm{s}, \max }$ in the active material, which is also important for later simulations. The theoretical capacity thus refers to a massive block of the active material, without including the porosity.

To calculate the electrode volume, it was assumed that only the regions which have a directly opposite positive electrode are active on the negative electrode. Accordingly, the active area for both electrodes because of the two coils and double-sided coating is $4 \times 375.0 \times$ $11.85 \mathrm{~cm}^{2}=1.7775 \mathrm{~m}^{2}$. The thicknesses for anode and cathode are taken from Table III while the measured electrode capacity is taken from the calculation of the full-cell balancing.

The ratio between the measured capacity $C_{\text {meas }}$ and the theoretical capacity $C_{\text {theo }}$ is formed to calculate the active material share $\epsilon_{\mathrm{s}}$ on the total volume of the electrode:

$$
\epsilon_{\mathrm{s}}=\frac{C_{\text {meas }}}{C_{\text {theo }}}
$$

For the negative electrode, an active material share of $49.25 \%$ is obtained, and the positive electrode of $56.74 \%$. This proportion corresponds to a perfect and completely usable material. Combined with the porosity of $29.2 \%$ for the negative and $20.9 \%$ for the positive electrode a remaining part of approx. $20 \%$ inactive material is calculated for both electrodes. In reality, however, the share of active material is presumably higher, but this material is then not fully usable.

The calculation of the surface $S$ is based on the assumption of $n$ ideal spherical particles with the previously determined mean radius $r$ from the Table III:

$$
A=n \cdot A_{\text {sphere }}=\frac{V \cdot \epsilon_{s}}{V_{\text {sphere }}} \cdot A_{\text {sphere }}=\frac{3 \cdot V \cdot \epsilon_{\mathrm{s}}}{r}
$$

For the negative electrode, a surface of $19.43 \mathrm{~m}^{2}$ is calculated, and for the positive electrode a surface of $61.61 \mathrm{~m}^{2}$.

The required data and the resulting volume fractions of the active material as well as the surfaces are summarized in Table IV.

\section{Parameters from Literature}

In the course of this work many parameters of the examined LIB were directly determined. However, two parameters could not be measured and have therefore to be taken from the literature. These are the transference number of the electrolyte and the conductivity of the electrode material.

For the transference number $t_{+}$of this electrolyte (EC/DMC/EMC 1:1:1 weight-\%) with $\mathrm{LiPF}_{6}$ as conducting salt $(1 \mathrm{~mol} / \mathrm{l})$ no values could be found in literature. A very comprehensive overview of the different methods for determining the transference number and a summary of the measured values can be found in Ref. 48 . Two electrolytes with $\mathrm{LiPF}_{6}$ and the solvents used here are listed there: For EC/EMC (1:1) a transference number of 0.38 was determined by Ref. 49 . In Ref. 50 EC/DMC (1:1) was examined, resulting in a transference number of 0.21 . The difference between the two values might be not only due to the different solvents, but also due to the different measuring methods. A further electrolyte study was carried out in Ref. 51 for EC/EMC (3:7) in dependency on the conductive salt concentration. This resulted in a concentration-dependent transference number ranging from about 0.38 for low concentrations down to 0.11 for high concentrations. Since no literature data could be found for the electrolyte used here and the other data are not consistent, a constant

\begin{tabular}{|c|c|c|c|c|c|c|c|c|}
\hline & $\begin{array}{c}\rho \\
\mathrm{g} / \mathrm{cm}^{3}\end{array}$ & $\begin{array}{c}V \\
\mathrm{~cm}^{3}\end{array}$ & $\begin{array}{c}M \\
\mathrm{~g} / \mathrm{mol}\end{array}$ & $\begin{array}{r}c_{\mathrm{s}, \max } \\
\mathrm{mol} / \mathrm{l}\end{array}$ & $\begin{array}{c}C_{\text {theo }} \\
\mathrm{Ah}\end{array}$ & $\begin{array}{c}C_{\text {meas }} \\
\text { Ah }\end{array}$ & $\begin{array}{l}\epsilon_{\mathrm{s}} \\
\%\end{array}$ & $\begin{array}{c}A \\
\mathrm{~m}^{2}\end{array}$ \\
\hline Anode & 2.26 & 82.83 & 72.0 & 31.39 & 69.68 & 34.32 & 49.25 & 19.43 \\
\hline Cathode & 4.67 & 76.43 & 96.5 & 48.39 & 99.13 & 56.74 & 57.24 & 61.61 \\
\hline
\end{tabular}

Table IV. Volume fraction $\epsilon_{\mathrm{s}}$ of the used active materials from the total volume and the surfaces $A$, each for anode and cathode. Additionally the values used for the calculation. The densities are taken from Ref. 46, [p. 51], and Ref. 47. 
transference number of 0.26 averaging the literature data is used for this work.

The conductivity of the porous electrode structure is usually significantly better than the conductivity of the electrolyte, at the same time the electrode is only present as a thin layer on the metallic current collector. In a previous work, the conductivity was measured across a double-coated sample, but this measurement contains, in addition to the electrode conductivity, the contact resistance to the current collector, which could not be separated. Since the electrode conductivity has only a very small influence on the model, the measurement has been omitted. Instead, reference is made to measuring results from Ref. 52. Three different cathode materials as well as graphite were examined and the conductivity of the electrode and the contact resistance to the current collector were determined in that work. In accordance with these results, a conductivity of $0.1 \mathrm{~S} / \mathrm{cm}$ for the positive electrode and of $10 \mathrm{~S} / \mathrm{cm}$ for the negative electrode are used.

\section{Conclusions}

Within this work almost all parameters needed for the parameterization of a physico-chemical model for a high-power prismatic cell were determined. For all parameters a short description of the measurement process is given to allow a transfer to other cells.

The analysis of the electrolyte's solvent components and conducting salt revealed a mixture of EC/DMC/EMC with $\mathrm{LiPF}_{6}$. The ionic conductivity of this mixture was determined for different conducting salt concentrations and temperatures.

The composition of the electrodes was analyzed using ICP-OES. NMC and graphite could be found as positive and negative electrode materials. The porous structure was investigated by mercury porosimetry and porosity, particle radii and tortuosity were calculated. These data are specific for the cell under investigation which cannot be replaced by literature data.

From self-built coin cells the OCV of both electrodes could be retrieved using very slow discharge and charge cycles. The lithium diffusion of the active materials with its dependency on lithiation and temperature was determined by GITT. Both the exchange current density and the double layer capacitance were calculated from EIS spectra fitting.

The analysis of the full cell revealed the balancing as well as the active material share of both electrodes.

The comparison with literature values often showed a wide spread of the available data, due to differences in the materials as well as the interaction between the individual components in a battery system. This also illustrates the relevance of the determination of all parameters directly from the cell to be simulated, compared to the pure collation of literature data, as is often done for simulations. A full list of all parameters is given in the second part of this paper, ${ }^{19}$ together with a simple thermal parameterization and a validation of the complete model and parameterization.

\section{Acknowledgment}

This work has been done during the time as an associated member of the research training group 'mobilEM' (GRK 1856/1). The authors would like to thank Fabian Frie, Rita Graff, Izaro Laresgoiti, Meinert Lewerenz, Jens Münnix, Jan-Hendrik Schöbel and Alexander Warnecke for the measurements done within this parameterization and Moritz Teuber for proofreading.

\section{ORCID}

Johannes Schmalstieg (1D https://orcid.org/0000-0002-0695-6762

\section{References}

1. J. Newman and W. Tiedemann, Porous-Electrode Theory with Battery Applications, AIChE Journal, 21(1), 25 (1975)
2. P. Ramadass, B. Haran, P. M. Gomadam, R. White, and B. N. Popov, Development of First Principles Capacity Fade Model for Li-Ion Cells, Journal of The Electrochemical Society, 151(2), A196 (2004).

3. J. Christensen and J. Newman, A Mathematical Model for the Lithium-Ion Negative Electrode Solid Electrolyte Interphase, Journal of The Electrochemical Society 151(11), A1977 (2004).

4. P. Arora, M. Doyle, and R. E. White, Mathematical modeling of the lithium deposition overcharge reaction in lithium-ion batteries using carbon-based negative electrodes, Journal of The Electrochemical Society, 146(10), 3543 (1999).

5. I. Laresgoiti, S. Käbitz, M. Ecker, and D. U. Sauer, Modeling mechanical degradation in lithium ion batteries during cycling: Solid electrolyte interphase fracture, Journal of Power Sources, 300, 112 (2015).

6. I. J. Ong, Double-Layer Capacitance in a Dual Lithium Ion Insertion Cell, Journa of The Electrochemical Society, 146(12), 4360 (1999).

7. M. Doyle, J. P. Meyers, and J. Newman, Computer Simulations of the Impedance Response of Lithium Rechargeable Batteries, Journal of The Electrochemical Society, 147(1), 99 (2000).

8. R. Darling and J. Newman, Modeling a Porous Intercalation Electrode with Two Characteristic Particle Sizes, Journal of The Electrochemical Society, 144(12), 4201 (1997).

9. P. Albertus, J. Christensen, and J. Newman, Experiments on and Modeling of Positive Electrodes with Multiple Active Materials for Lithium-Ion Batteries, Journal of The Electrochemical Society, 156(7), A606 (2009).

10. M. Tang, P. Albertus, and J. Newman, Two-Dimensional Modeling of Lithium Deposition during Cell Charging, Journal of The Electrochemical Society, 156(5), A390 (2009).

11. M. Ecker, T. Tran, P. Dechent, S. Käbitz, A. Warnecke, and D. Sauer, Parameterization of a Physico-Chemical Model of a Lithium-Ion Battery: I. Determination of Parameters, Journal of the Electrochemical Society, 162(9), A1836 (2015).

12. M. Ecker, S. Käbitz, I. Laresgoiti, and D. U. Sauer, Parameterization of a PhysicoChemical Model of a Lithium-Ion Battery: II. Model Validation, Journal of the Electrochemical Society, 162 (2015) A1849.

13. M. Ecker, Lithium Plating in Lithium-Ion Batteries - An Experimental and Simulation Approach, PhD thesis, RWTH Aachen (2016).

14. M. D. Levi and D. Aurbach, Diffusion coefficients of lithium ions during intercalation into graphite derived from the simultaneous measurements and modeling of electrochemical impedance and potentiostatic intermittent titration characteristics of thin graphite electrodes, Journal of Physical Chemistry B, 101(23), 4641 (1997).

15. T. Piao, Intercalation of Lithium Ions into Graphite Electrodes Studied by AC Impedance Measurements, Journal of The Electrochemical Society, 146(8), 2794 (1999).

16. A. Funabiki, Impedance Study on the Electrochemical Lithium Intercalation into Natural Graphite Powder, Journal of The Electrochemical Society, 145(1), 172 (1998).

17. M. Inaba, Secondary batteries - lithium rechargable systems - lithium-ion | negative elektrodes: Graphite, in: J. Garche, C. K. Dyer, P. T. Moseley, Z. Ogumi, D. A. J. Rand, B. Scrosati (Eds.), Encyclopedia of Electrochemical Power Sources, Vol. 5 , Elsevier, Amsterdam, 2009, pp. 198-208.

18. J. Schmalstieg, Physikalisch-elektrochemische Simulation von Lithium-Ionen-Batterien: Implementierung, Parametrierung und Anwendung, PhD thesis, RWTH Aachen University, Aachen (2017)

19. J. Schmalstieg and D. U. Sauer, Full Cell Parameterization of a High-Power LithiumIon Battery for a Physico-Chemical Model: Part II. Thermal Parameters and Validation, Journal of The Electrochemical Society, 165 (16), A3811 (2018).

20. D. L. Wood, J. Li, and C. Daniel, Prospects for reducing the processing cost of lithium ion batteries, Journal of Power Sources, 275, 234 (2015).

21. D. Chung, E. Elgqvist, and S. Santhanagopalan, Automotive lithium-ion cell manufacturing: Regional cost structures and supply chain considerations, techreport, National Renewable Energy Laboratory (NREL) (2016).

22. BASF, http://catalystsinfo.com/downloads/public/pdfs/Battery for enhanced battery performance, online, Stand 17. Januar 2017 (2015).

23. M. Ue, Secondary batteries - lithium rechargeable systems | electrolytes: Nonaqueous, in: J. Garche, C. K. Dyer, P. T. Moseley, Z. Ogumi, D. A. J. Rand, B. Scrosati (Eds.) Encyclopedia of Electrochemical Power Sources, Vol. 5, Elsevier, Amsterdam, 2009, pp. 71-84.

24. L. O. Valøen and J. N. Reimers, Transport Properties of $\mathrm{LiPF}_{6}$-Based Li-Ion Battery Electrolytes, Journal of The Electrochemical Society, 152(5), A882 (2005).

25. C. Czeslik, H. Seemann, and R. Winter, Basiswissen Physikalische Chemie, 2nd Edition, Teubner, Wiesbaden, 2007.

26. M. Ender, Mikrostrukturelle Charakterisierung, Modellentwicklung und Simulation poröser Elektroden für Lithiumionenzellen, PhD thesis, KIT (2014).

27. S. S. Zhang, A review on the separators of liquid electrolyte Li-ion batteries, Journal of Power Sources, 164(1), 351 (2007).

28. C. J. Weber and M. Roth, Separatoren, in: R. Korthauer (Ed.), Handbuch LithiumIonen-Batterien, Springer-Verlag, Berlin Heidelberg, 2013, pp. 31-44.

29. S. C. Carniglia, Construction of the tortuosity factor from porosimetry, Journal of Catalysis, 102(2), 401 (1986)

30. K. K. Patel, J. M. Paulsen, and J. Desilvestro, Numerical simulation of porous networks in relation to battery electrodes and separators, Journal of Power Sources, 122(2), 144 (2003).

31. R. P. Mayer and R. A. Stowe, Mercury porosimetry - breakthrough pressure for penetration between packed spheres, Journal of Colloid Science, 20(8), 893 (1965).

32. F. N. Fritsch and R. E. Carlson, Monotone Piecewise Cubic Interpolation, SIAM Journal on Numerical Analysis, 17(2), 238 (1980). 
33. W. Weppner, Determination of the Kinetic Parameters of Mixed-Conducting Electrodes and Application to the System $\mathrm{Li}_{3} \mathrm{Sb}$, Journal of The Electrochemical Society, 124(10), 1569 (1977).

34. R. A. Huggins, Transient behavior of insertion reaction electrodes, Solid State Ionics, 86-88(1), 41 (1996)

35. S.-L. Wu, W. Zhang, X. Song, A. K. Shukla, G. Liu, and V. Battaglia, V. Srinivasan,High Rate Capability of $\mathrm{Li}\left(\mathrm{Ni}_{1 / 3} \mathrm{Mn}_{1 / 3} \mathrm{Co}_{1 / 3}\right) \mathrm{O}_{2}$ Electrode for Li-Ion Batteries, Journal of The Electrochemical Society, 159(4), A438 (2012).

36. Y. Idemoto and T. Matsui, Thermodynamic stability, crystal structure, and cathodic performance of $\mathrm{Li}_{\mathrm{x}}\left(\mathrm{Mn}_{1 / 3} \mathrm{Co}_{1 / 3} \mathrm{Ni}_{1 / 3}\right) \mathrm{O}_{2}$ depend on the synthetic process and $\mathrm{Li}$ content, Solid State Ionics, 179(17-18), 625 (2008).

37. H. J. Noh, S. Youn, C. S. Yoon, and Y. K. Sun, Comparison of the structural and electrochemical properties of layered $\mathrm{Li}\left[\mathrm{Ni}_{\mathrm{x}} \mathrm{Co}_{\mathrm{y}} \mathrm{Mn}_{\mathrm{z}}\right] \mathrm{O}_{2}(\mathrm{x}=1 / 3,0.5,0.6,0.7,0.8$ and 0.85 ) cathode material for lithium-ion batteries, Journal of Power Sources, 233, 121 (2013).

38. T. L. Kulova, A. M. Skundin, E. A. Nizhnikovskii, and A. V. Fesenko, Temperature effect on the lithium diffusion rate in graphite, Russian Journal of Electrochemistry, 42(3), 259 (2006)

39. K. Toyoura, Y. Koyama, A. Kuwabara, F. Oba, and I. Tanaka, First-principles approach to chemical diffusion of lithium atoms in a graphite intercalation compound, Physical Review B - Condensed Matter and Materials Physics, 78(21), 1 (2008).

40. S. Cui, Y. Wei, T. Liu, W. Deng, Z. Hu, Y. Su, H. Li, M. Li, H. Guo, Y. Duan, W. Wang, M. Rao, J. Zheng, X. Wang, and F. Pan, Optimized Temperature Effect of Li-Ion Diffusion with Layer Distance in $\mathrm{Li}\left(\mathrm{Ni}_{\mathrm{x}} \mathrm{Mn}_{\mathrm{y}} \mathrm{Co}_{\mathrm{z}}\right) \mathrm{O}_{2}$ Cathode Materials for High Performance Li-Ion Battery, Advanced Energy Materials, 6(4), 1 (2016).

41. H. Witzenhausen, Elektrische Batteriespeichermodelle: Modellbildung, Parameteridentifikation und Modellreduktion, PhD thesis, RWTH Aachen (2017).

42. J. Newman, K. E. Thomas, and R. M. Darling, Mathematical modeling of lithium batteries, in: W. A. van Schalkwijk, B. Scrosati (Eds.), Advances in Lithium-Ion
Batteries, Kluwer Academic Publishers, New York, Boston, Dordrecht, London, Moskau, 2002, pp. 345-392.

43. M. C. Smart and B. V. Ratnakumar, Effects of Electrolyte Composition on Lithium Plating in Lithium-Ion Cells, Journal of The Electrochemical Society, 158(4), A379 (2011).

44. S. Tippmann, Modellierung und experimentelle Charakterisierung des Degradationsverhaltens durch Lithium-Plating an Lithium-Ionen-Zellen unter automobilen Betriebsbedingungen, $\mathrm{PhD}$ thesis, Universität Stuttgart (2016).

45. J. Xu, S.-L. Chou, Q.-f. Gu, H.-K. Liu, and S.-X. Dou, The effect of different binders on electrochemical properties of $\mathrm{LiNi}_{1 / 3} \mathrm{Mn}_{1 / 3} \mathrm{Co}_{1 / 3} \mathrm{O}_{2}$ cathode material in lithium ion batteries, Journal of Power Sources, 225, 172 (2013).

46. H. O. Pierson, Handbook of Carbon, Graphite, Diamonds and Fullerenes - Processing, Properties and Applications, 1st Edition, Noyes Publications, Park Ridge, 1993.

47. $\mathrm{Li}\left[\mathrm{ni}_{1 / 3} \mathrm{Co}_{1 / 3} \mathrm{mn}_{1 / 3}\right] \mathrm{o}_{2}$ crystal structure: Datasheet from "pauling file multinaries edition - 2012" in springermaterials, online, Stand 20. Januar 2017 (2016)

48. C. Daniel and J. O. Besenhard, Handbook of Battery Materials, 2nd Edition, John Wiley \& Sons, New York, 2012

49. S. Stewart and J. Newman, Measuring the Salt Activity Coefficient in LithiumBattery Electrolytes, Journal of the Electrochemical Society, 155(6), A458 (2008).

50. L. F. Li, H. S. Lee, H. Li, X. Q. Yang, K. W. Nam, W. S. Yoon, J. McBreen, and X. J. Huang, New electrolytes for lithium ion batteries using LiF salt and boron based anion receptors, Journal of Power Sources, 184(2), 517 (2008).

51. A. Nyman, M. Behm, and G. Lindbergh, Electrochemical characterisation and modeling of the mass transport phenomena in $\mathrm{LiPF}_{6}$-EC-EMC electrolyte, Electrochimica Acta, 53(22), 6356 (2008).

52. M. Ender, A. Weber, and E. Ivers-Tiffée, A novel method for measuring the effective conductivity and the contact resistance of porous electrodes for lithium-ion batteries, Electrochemistry Communications, 34, 130 (2013). 